\title{
Melorheostosis with osteopoikilosis
}

INSERM

\section{Source}

INSERM. (1999). Orphanet: an online rare disease and orphan drug data base.

Melorheostosis with osteopoikilosis. ORPHA:1879

Melorheostosis with osteopoikilosis is a rare sclerosing bone dysplasia, combining the clinical and radiological features of melorheostosis and osteopoikilosis (see these terms), that has been reported in some families with osteopoikilosis and that is characterized by a variable presentation of limb pain and deformities. 